\title{
Dietary Iron Intake in Women of Reproductive Age in Europe: A Review of 49 Studies from 29 Countries in the Period 1993-2015
}

\author{
Nils Thorm Milman (iD \\ Department of Clinical Biochemistry, Nestved Hospital, University College Zealand, DK-4700 Noestved, Denmark \\ Correspondence should be addressed to Nils Thorm Milman; nils.milman@outlook.com
}

Received 7 January 2019; Revised 5 May 2019; Accepted 26 May 2019; Published 13 June 2019

Academic Editor: Luigi Schiavo

Copyright (c) 2019 Nils Thorm Milman. This is an open access article distributed under the Creative Commons Attribution License, which permits unrestricted use, distribution, and reproduction in any medium, provided the original work is properly cited.

\begin{abstract}
Objective. Assessment of dietary iron intake in women of reproductive age in Europe. Design. Review. Setting. Literature search of dietary surveys reporting intake of iron using PubMed, Internet browsers, and national nutrient databases in the period 1993-2015. Subjects. Women of reproductive age. Results. 49 dietary surveys/studies in 29 European countries were included. Belgium, Bosnia, Denmark, Hungary, Italy, Northern Ireland, Serbia, Scotland, Sweden, Switzerland, United Kingdom/England, and Wales reported a median/mean iron intake of 7.6-9.9 mg/day. Finland, Iceland, Ireland, the Netherlands, Norway, Poland, and Spain reported an intake of 10.0-10.7 mg/day. Austria, Estonia, France, and Russia reported an intake of 11.0-11.9 mg/day. Latvia and Germany reported an intake of 12.0-12.2 mg/day. Croatia, Lithuania, Portugal, and Slovakia reported an intake of $15.9-19.0 \mathrm{mg} /$ day. The percentage of dietary iron consisting of heme iron, reported in 7 studies, varied from $4.3 \%$ in United Kingdom to $25 \%$ in Spain. Nutrient density for iron (mg iron/10 MJ, median/mean) varied from 11.8 in Sweden to 23.0 in Lithuania. The correlation between nutrient density and dietary iron was significant $(p=0.0006)$. In most countries, the majority of women had a dietary iron intake below $15 \mathrm{mg}$ /day. In Belgium, Denmark, Hungary, and Sweden, 91-95\% of women had an intake below $15 \mathrm{mg}$ /day. In Ireland and Germany, 61-78\% had an intake below $15 \mathrm{mg} /$ day. Conclusions. In Europe, 61-97\% of women have a dietary iron intake below $15 \mathrm{mg}$ /day. This contributes to a low iron status in many women. We need common European standardized dietary methods, uniform dietary reference values, and uniform statistical methods to perform intercountry comparisons.
\end{abstract}

\section{Introduction}

In healthy humans, the body iron input is generated by gastrointestinal absorption of dietary iron [1]. Body iron losses are composed of basal (obligatory) losses, which are quite similar in men and women [1]. In addition, women in the reproductive age have considerable physiological iron losses associated with menstruations $[2,3]$ and pregnancies [4]. Both iron deficiency [5] and iron overload [6] will affect body functions in negative ways and impair quality of life and survival.

The World Health Organization's (WHO) latest report on the global prevalence of anemia [7] states that, in the European Region, among nonpregnant women of 1549 years of age, $22.5 \%$ have anemia, predominantly due to iron deficiency (ID).
The high physiological iron losses in women of reproductive age pose demands on iron absorption, which in turn is dependent on the quantitative and qualitative intake of dietary iron. A recent review of body iron status in women of reproductive age in Europe [8] showed that approximately $40-55 \%$ have small or absent body iron reserves, i.e., serum ferritin $\leq 30 \mu \mathrm{g} / \mathrm{L}$. The prevalence of ID was $10-32 \%$ and of iron deficiency anemia (IDA) $2-5 \%$. Approximately $20-35 \%$ of women had sufficient iron reserves (serum ferritin $>70 \mu \mathrm{g} / \mathrm{L}$ ) which could enable them to complete a pregnancy without taking supplementary iron [8]. The low iron status in the majority of European women may in part be due to an inadequate dietary iron intake, a low intake of heme iron, and/or an inappropriate balance between the content of enhancers and inhibitors of iron absorption in the diet. 
The objective of this paper was to provide a review of surveys and studies assessing dietary iron intake in nonpregnant women of reproductive age in Europe and to address to which degree dietary iron intake corresponds to the recommended intake in the respective countries.

\section{Methods}

We conducted literature searches in PubMed and on the Internet using the browsers Google Chrome, Google Scholar, and Edge applying the key words "dietary iron intake," "dietary iron intake in... name of country," and "dietary survey in... name of country." Search was performed for all the European countries. We included studies from The European Nutrition and Health Report 2009 [9] and studies from The European Food Safety Authority (EFSA) paper on iron 2015 [10] as well as in the EFSA paper on Dietary Reference Values 2017 [11]. We consulted the EFSA food composition database but could not obtain access to the data on micronutrients. Some studies were identified from references in original papers.

We consulted a paper about information on European national dietary surveys [12] and a paper on European food databases [13]. Several national institutes of nutrition were contacted to obtain information about dietary iron intake. We located no studies from Slovenia and Cyprus and could not obtain information from Greece and North Macedonia and from the Eastern European countries Belarus, Bulgaria, Czech Republic, Moldova, Romania, and Ukraine.

Only surveys/studies reporting the intake of dietary iron per se were included in this review. Five studies, which reported the total iron intake, e.g., dietary plus supplemental iron intake but did not specify the dietary iron intake per se, were not included in this review.

In the statistical interpretation of the results, it is important to consider the overall distribution of dietary iron intake when evaluating the prevalence of an inadequate iron intake. If the distribution is normal, it is relatively simple to calculate and define inadequacy using parametric statistics with arithmetic mean and standard deviation. In case of an asymmetric distribution skewed to the right, with a higher frequency of low values, the median is lower than the arithmetic mean. Therefore, using the arithmetic mean in skewed data will tend to underestimate the prevalence of inadequacy, and nonparametric statistics should be used instead.

\section{Results}

Most reports were in English language, but we managed to interpret reports published in Dutch, Finnish, French, German, Hungarian, Icelandic, and Spanish languages. We decided to include all the identified reports, irrespective of the dietary method used, in order to demonstrate some of the differences between the dietary methods.

An overview of the 49 included European surveys/ studies [14-58] on dietary iron intake in women of predominantly reproductive age performed in 29 countries during the period 1993 to 2015 is shown in Table 1.
In Europe, the age interval for assessing iron intake in women of reproductive age should probably be 20-45 years; on the average, in 2015, across the European Union (EU), the mean age of women was 29 years when they became mothers for the first time and the proportion of teenage mothers less than 20 -year-old was on the average $4 \%$, being lowest in the Western EU countries [59]. After the age of 45 years, fertility is markedly reduced; the median age at menopause among white women from industrialized countries ranges between 50 and 52 years and the onset of the perimenopause is 47.5 years [60]. However, many studies used an age interval of 18-64 years, and we had no opportunity to recalculate the results in the 20-45 years interval. However, due to the relative age composition of the women in the respective population groups, the majority was in the reproductive (premenopausal) age, i.e., 20-45 years of age. Furthermore, dietary iron intake was not significantly different in premenopausal and postmenopausal women up to the age of approximately 64 years. This was apparent in studies from Denmark [21, 22], the Baltic Republics [23], Finland [24], France [26], the Netherlands [38, 39], Scotland [46], Serbia [47], United Kingdom (UK) [56, 57], and Wales [58]. Therefore, we decided to include the entire group of women aged 18-64 years. For reasons of comparison, values for dietary iron intake in postmenopausal women are also shown in Table 1. Evidently, dietary iron intake was quite similar in premenopausal women and women in the early postmenopausal years.

The dietary survey method varied between the studies (Table 1). The most frequent method was food diary registration for 2-7 days. The second most used dietary method was 24-hour dietary recall. A single 24-hour dietary recall was used in 11 studies and 24-hour dietary recall $\times 2-3$ in 11 studies. Four studies used Food Frequency Questionnaires (FFQ), and three German studies used a dietary history interview.

The food composition tables used to calculate dietary iron intake were in most countries based on national nutrient databases. The Baltic Republics used Russian-based food composition tables from the early 1980s and some of the East European countries used USA-based food composition tables, which were adapted for national use.

In the statistical handling of the data, most of the studies used unweighted population data, while 12 studies used weighted data in order to adjust the study sample for the age and gender composition of the entire population in the country.

Dietary heme iron intake was reported in 7 studies (Table 1). The mean percentage of dietary iron intake consisting of heme iron displayed great variation from $4.3 \%$ in UK, 5.7\% in Belgium, 10.3\% in Russia, 10.4\% in France, $14.5 \%$ in the Netherlands to $20.1 \%$, and $29.7 \%$ in Spain.

Nutrient density is the content of a food component per unit of energy. Nutrient density for iron in mg iron per 10 MJ was reported from 9 countries, as shown in Table 2. The median or mean nutrient density varied from 11.8 in Sweden to $23.0 \mathrm{mg}$ iron/10 MJ in Lithuania. Using the data from the various countries, we found a significant correlation between nutrient density for iron and dietary 


\begin{tabular}{|c|c|c|c|c|c|c|c|c|c|c|c|c|c|c|c|}
\hline 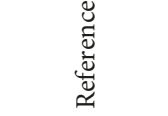 & $\Xi$ & 氖 & $\stackrel{\Xi}{=}$ & $\Xi$ & $\stackrel{\infty}{\Xi}$ & $\bar{\Xi}$ & $\overline{\stackrel{d}{I}}$ & $\bar{\Xi}$ & $\bar{\Xi}$ & $\overline{\vec{\Xi}}$ & $\overline{\mathbb{Z}}$ & $\overline{\mathbb{Z}}$ & $\overline{\mathbb{Z}}$ & $\overline{\widetilde{\Xi}}$ & $\overline{\widetilde{\Omega}}$ \\
\hline 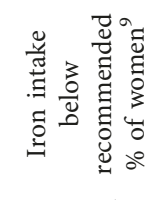 & 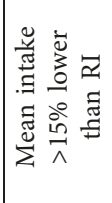 & I & 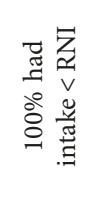 & 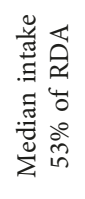 & 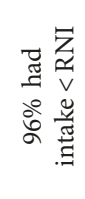 & 尊 & 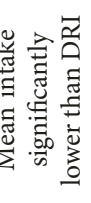 & I & I & I & 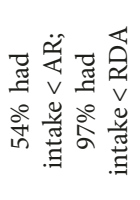 & I & I & I & | \\
\hline 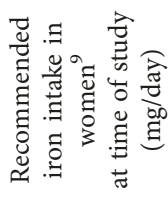 & $\stackrel{\sim n}{\vec{a}}$ & $\stackrel{\mathscr{2}}{\overparen{a}}$ & $\stackrel{\stackrel{N}{\Xi}}{\underset{z}{n}}$ & $\begin{array}{l}\stackrel{\AA}{1} \\
\overleftrightarrow{a} \\
\text { a }\end{array}$ & 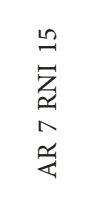 & $\stackrel{\infty}{\overleftrightarrow{a}}$ & $\stackrel{\infty}{\overrightarrow{\tilde{a}}}$ & $\begin{array}{l}\stackrel{n}{2} \\
\stackrel{4}{a}\end{array}$ & $\begin{array}{l}\stackrel{n}{7} \\
\stackrel{4}{a}\end{array}$ & $\begin{array}{l}\text { n } \\
\text { 苑 }\end{array}$ & 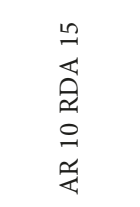 & $\begin{array}{l}\stackrel{n}{2} \\
\stackrel{4}{a}\end{array}$ & 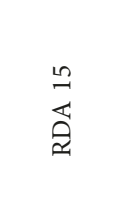 & 1 & | \\
\hline 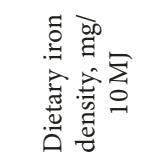 & I & I & I & 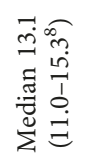 & I & I & I & I & I & 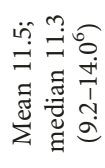 & I & I & 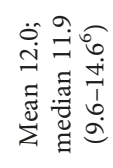 & 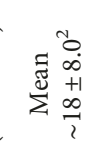 & 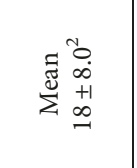 \\
\hline 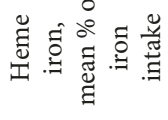 & I & I & I & $\hat{\text { in }}$ & I & I & I & I & I & I & I & I & I & I & I \\
\hline 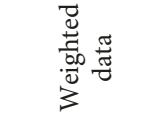 & $\stackrel{\circ}{z}$ & 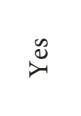 & z̊ & ż & z̊ & $\stackrel{\circ}{z}$ & $\stackrel{\circ}{z}$ & ż & $\dot{z}$ & ż & ż & ż & z̊ & ż & ฉ̊ \\
\hline 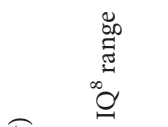 & I & I & 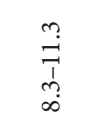 & $\begin{array}{l}\stackrel{\infty}{i} \\
\stackrel{1}{1} \\
\stackrel{a}{a}\end{array}$ & I & I & I & $\begin{array}{l}n \\
\stackrel{n}{I} \\
\stackrel{1}{n}\end{array}$ & 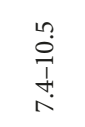 & I & $\stackrel{\substack{n \\
=}}{=}$ & 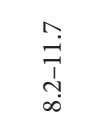 & I & I & 1 \\
\hline 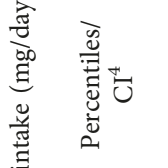 & I & 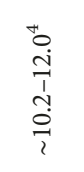 & I & I & $\begin{array}{l}\text { ra } \\
0 \\
0 \\
i \\
0 \\
\infty\end{array}$ & I & I & 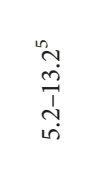 & 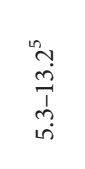 & $\begin{array}{l}0 \\
\stackrel{0}{0} \\
\stackrel{1}{1} \\
i \\
6\end{array}$ & 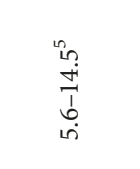 & 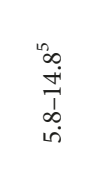 & 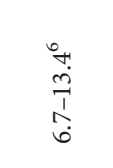 & I & \\
\hline 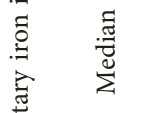 & I & I & $\hat{a}$ & $\stackrel{0}{\circ}$ & I & I & I & $\underset{\infty}{\infty}$ & $\begin{array}{l}\infty \\
\infty \\
\infty\end{array}$ & $\begin{array}{l}\infty \\
\infty \\
\infty\end{array}$ & $\hat{\sigma}$ & $\dot{\sigma}$ & $\stackrel{\infty}{a}$ & $=$ & $\stackrel{ }{\circ}$ \\
\hline 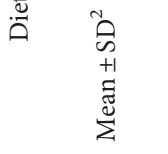 & 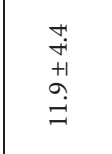 & $\stackrel{\circ}{\overrightarrow{7}}$ & $\begin{array}{l}\text { ris } \\
+1 \\
\stackrel{+}{a}\end{array}$ & I & $\vec{\infty}_{\infty}$ & $\begin{array}{l}\stackrel{a}{a} \\
+1 \\
0 \\
0\end{array}$ & $\begin{array}{l}a \\
\stackrel{2}{+1} \\
+\overrightarrow{0}\end{array}$ & $\begin{array}{l}i n \\
\stackrel{1}{i} \\
+1 \\
0 \\
0\end{array}$ & $\begin{array}{l}\stackrel{+}{i} \\
\stackrel{+}{+} \\
\stackrel{a}{a}\end{array}$ & $\begin{array}{l}\stackrel{n}{i} \\
i \\
+1 \\
0 \\
0\end{array}$ & $\begin{array}{l}\hat{a} \\
+1 \\
\dot{a}\end{array}$ & $\begin{array}{l}\infty \\
\stackrel{\infty}{i} \\
+1 \\
\stackrel{+}{+}\end{array}$ & $\begin{array}{l}\stackrel{a}{i} \\
+ \\
\stackrel{+}{0} \\
\stackrel{9}{\oplus}\end{array}$ & $\begin{array}{l}+ \\
\stackrel{+1}{I}\end{array}$ & $\stackrel{+}{+1}$ \\
\hline 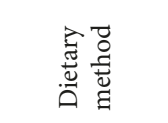 & 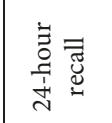 & 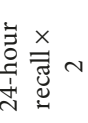 & 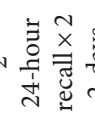 & 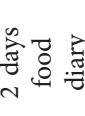 & $\bar{x}$ & 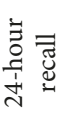 & $\begin{array}{l}0 \\
0 \\
0 \\
0 \\
1\end{array}$ & 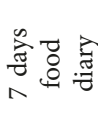 & 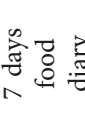 & 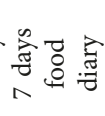 & 产总高 & 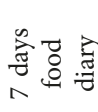 & 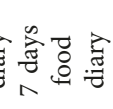 & 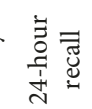 & 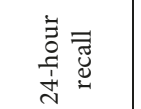 \\
\hline 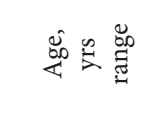 & $\begin{array}{l}+ \\
\vdots \\
\vdots \\
\text { ఏ }\end{array}$ & 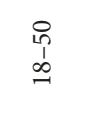 & $\begin{array}{l}\hat{\omega} \\
\hat{\jmath} \\
\text { a }\end{array}$ & $\begin{array}{c}\infty \\
\hat{0} \\
\infty \\
\infty\end{array}$ & \begin{tabular}{c}
$\infty$ \\
$\hat{0}$ \\
$\infty$ \\
\hdashline
\end{tabular} & $\begin{array}{l}0 \\
0 \\
1 \\
\infty \\
-1\end{array}$ & $\begin{array}{l}\text { o } \\
\infty \\
\infty \\
\infty\end{array}$ & $\begin{array}{l}\stackrel{2}{2} \\
\infty \\
\infty \\
\sim\end{array}$ & $\begin{array}{l}+4 \\
\vdots \\
\text { İ }\end{array}$ & 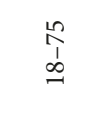 & $\begin{array}{l}\text { for } \\
\text { of } \\
\text { D. }\end{array}$ & $\begin{array}{l}\text { मे } \\
\text { ఏ }\end{array}$ & 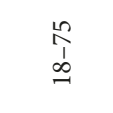 & $\begin{array}{l}\text { शे } \\
\text { I }\end{array}$ & 怘 \\
\hline 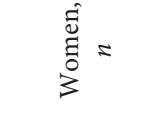 & $\stackrel{\stackrel{2}{2}}{\mathrm{~m}}$ & $\stackrel{\infty}{=}$ & \& & Fै & 유 & $\underset{\substack{7 \\
i}}{2}$ & $\stackrel{\infty}{\infty}$ & $\tilde{\kappa}$ & ڤે & $\stackrel{\infty}{\stackrel{\infty}{\beth}}$ & $\stackrel{\circ}{\circ}$ & ঐิ త్ & 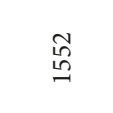 & $\stackrel{\infty}{\infty}_{\infty}^{\infty}$ & 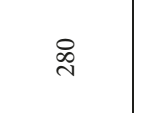 \\
\hline 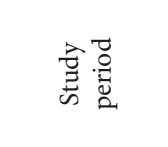 & ڤ્̀ે & $\vec{i}$ & 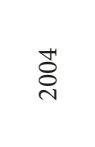 & 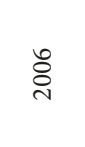 & $\vec{i}$ & 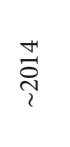 & ?ֶ. & 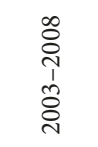 & 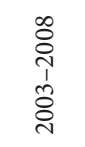 & 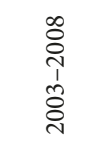 & $\begin{array}{l}m \\
\stackrel{\tilde{i}}{1} \\
\stackrel{\vec{n}}{\vec{N}}\end{array}$ & $\begin{array}{l}m \\
\stackrel{n}{i} \\
i \\
\vec{i} \\
\vec{i}\end{array}$ & $\begin{array}{c}m \\
\stackrel{n}{i} \\
\stackrel{i}{\vec{i}}\end{array}$ & ڤે & ลे \\
\hline 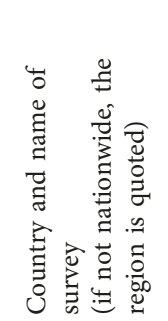 & 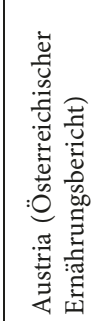 & 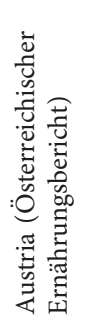 & 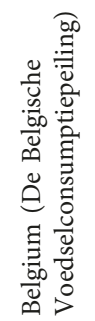 & 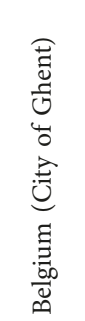 & 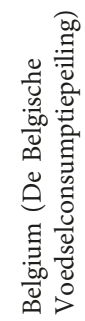 & 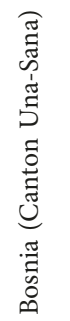 & 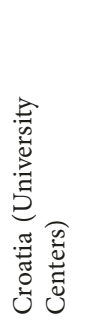 & 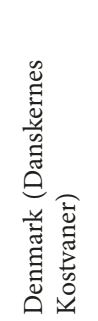 & 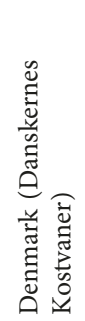 & 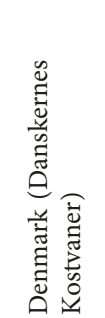 & 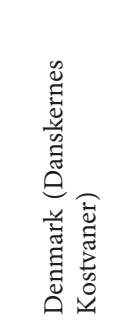 & 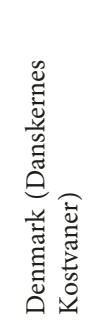 & 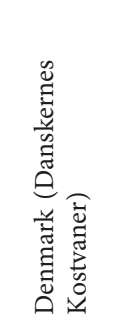 & 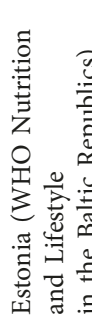 & 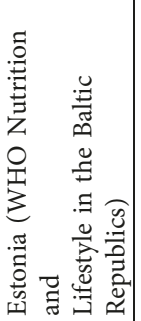 \\
\hline
\end{tabular}




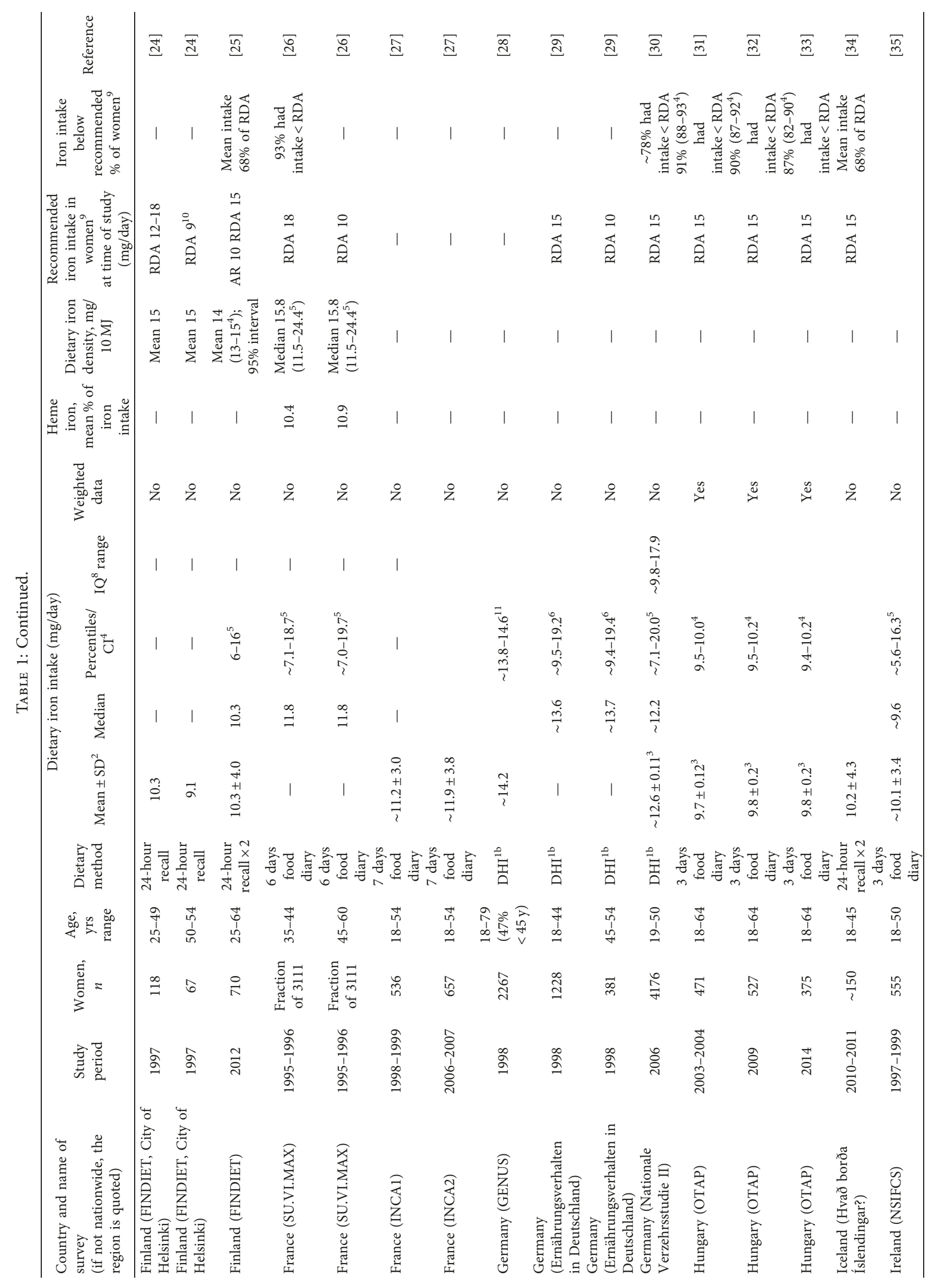




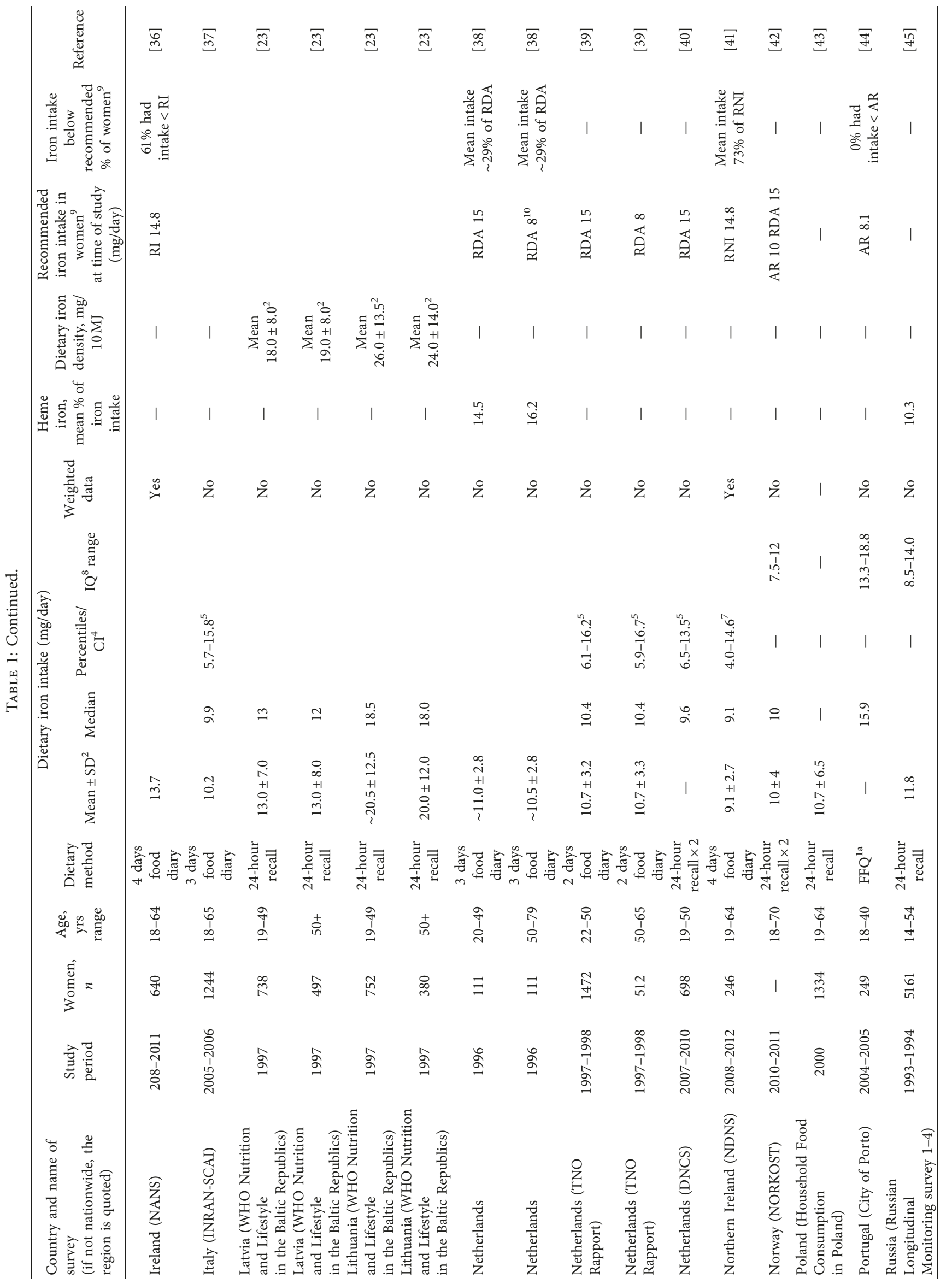




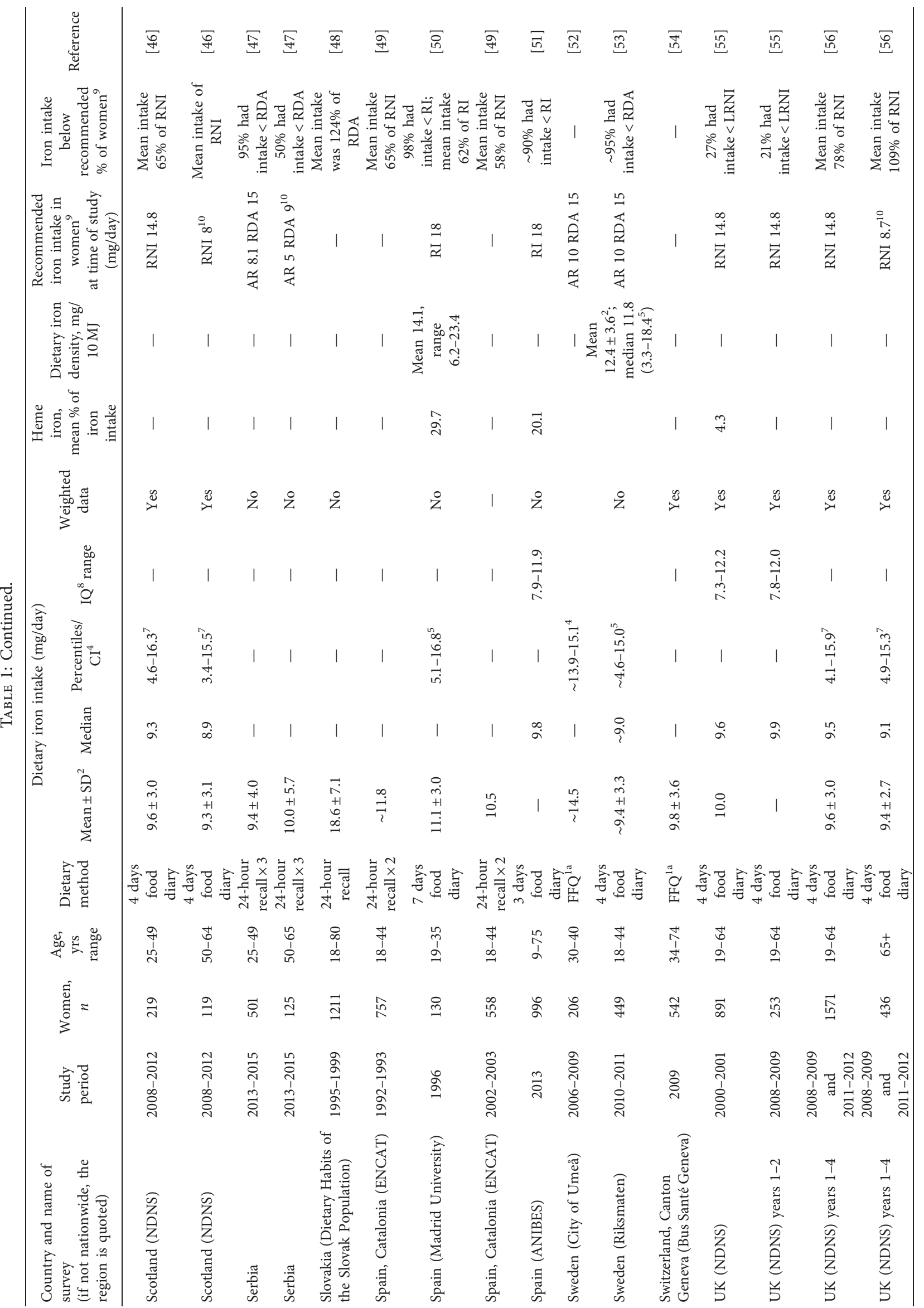




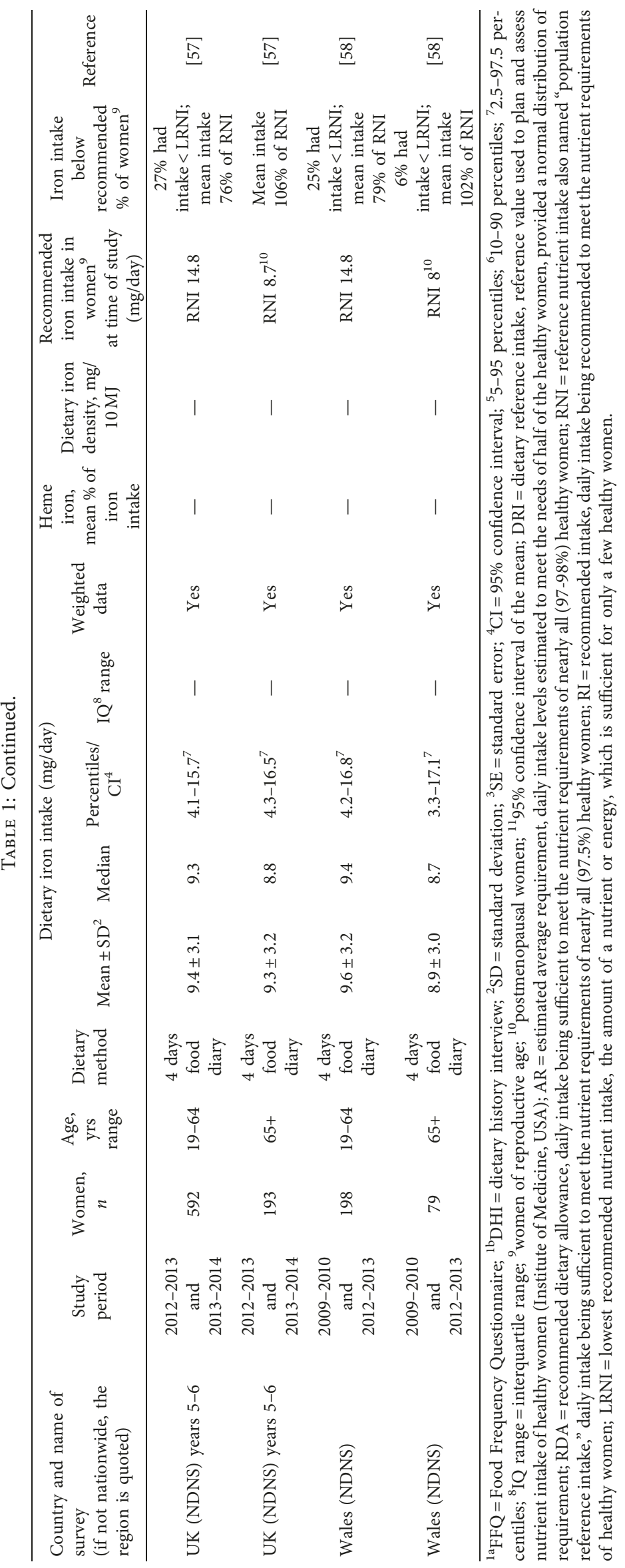


TABLE 2: Association between nutrient density for iron and dietary iron intake arranged according to the magnitude of nutrient density.

\begin{tabular}{lccc}
\hline Country & Reference & Dietary iron density $(\mathrm{mg} / 10 \mathrm{MJ})$ & Dietary iron intake (mg/day) \\
\hline Lithuania & {$[23]$} & $23.0^{1}$ & $19^{2}$ \\
Estonia & {$[23]$} & $17.0^{1}$ & $11^{1}$ \\
Latvia & {$[23]$} & $17.0^{1}$ & $12^{2}$ \\
France & {$[26]$} & $15.8^{2}$ & $11.8^{2}$ \\
Spain & {$[50]$} & $14.1^{1}$ & $11.1^{1}$ \\
Finland & {$[25]$} & $14.0^{1}$ & $10.3^{2}$ \\
Belgium & {$[17]$} & $13.1^{2}$ & $10.6^{2}$ \\
Denmark & {$[22]$} & $11.9^{2}$ & $9.8^{2}$ \\
Sweden & {$[53]$} & $11.8^{2}$ & $9.0^{2}$ \\
\hline
\end{tabular}

${ }^{1}$ Arithmetic mean; ${ }^{2}$ median; Spearman's $r h o=0.91, p=0.0006$.

iron intake, as shown in Table 2 (Spearman's $r h o=0.91$, $p=0.0006$ ).

Table 3 includes the latest and largest studies from the 29 countries arranged according to the magnitude of median or mean dietary iron intake.

There were considerable differences between the reported median or mean iron dietary intake in different countries. Twelve countries (Bosnia, Belgium, Sweden, Northern Ireland, Scotland, Wales, Serbia, UK including England, Denmark, Switzerland, Hungary, and Italy) reported median or mean iron intake ranging from 7.6 to $9.9 \mathrm{mg} /$ day. Norway, Iceland, Finland, the Netherlands, Spain, Poland, and Ireland reported iron intake from 10.0 to $10.7 \mathrm{mg} /$ day. Estonia, Russia, France, and Austria reported iron intake from 11.0 to $11.9 \mathrm{mg} /$ day. Latvia and Germany reported intake of 12.0 and $12.2 \mathrm{mg} /$ day, while Portugal, Croatia, Slovakia, and Lithuania reported intake from 15.9 to $19.0 \mathrm{mg} /$ day. The "estimated" median value of the reported median or mean dietary iron intake in all the countries shown in Table 3 was $10.2 \mathrm{mg} /$ day.

The estimated average requirement (AR) is the level of daily nutrient intake that is adequate for half of the people in a population group giving a normal distribution of requirement [61]. Using an estimated AR of $7 \mathrm{mg} /$ day for dietary iron intake in women of reproductive age (Table 4), more than $50 \%$ of women in all countries had an intake above AR, in some countries up to $70-100 \%$ (Table 3). Applying an AR of $10 \mathrm{mg} /$ day (Table 4), more than $50 \%$ of women in 13 countries had an intake below AR; in one country, the intake was equal to $\mathrm{AR}$, while in 15 countries, more than $50 \%$ of women had an intake above AR.

In the various studies, there was no consistence in the terminology and the use of Dietary Reference Values (DRV) for dietary iron intake. DRVs comprised recommended intake (RI), reference nutrient intake (RNI), recommended dietary allowance (RDA), dietary reference intake (DRI), or lowest recommended nutrient intake (LNRI). Only few studies reported the AR and none used the term "population reference intake" (PRI) as proposed by EFSA [61]. Many papers referred to national RI/RNI/RDAs but without quoting the actual values. There was a tendency that older studies recommended higher RI/RNI/RDA's values above $15 \mathrm{mg} /$ day than more recent studies, which showed increasing consensus towards a value of $14.8-16.0 \mathrm{mg} /$ day. However, the daily recommended intake of dietary iron
TABLE 3: Dietary iron intake in nonpregnant women of predominantly reproductive age in 29 European countries, arranged according to median or mean iron intake.

\begin{tabular}{lcc}
\hline Country & Reference & $\begin{array}{c}\text { Median or mean iron } \\
\text { intake }(\mathrm{mg} / \text { day) }\end{array}$ \\
\hline Lithuania & {$[23]$} & 18.5 \\
Slovakia & {$[48]$} & $18.6^{*}$ \\
Croatia & {$[20]$} & $16.1^{*}$ \\
Portugal & {$[44]$} & 15.9 \\
Germany & {$[30]$} & 12.2 \\
Latvia & {$[23]$} & 13.0 \\
Austria & {$[14]$} & $11.9^{*}$ \\
France & {$[27]$} & $11.9^{*}$ \\
Russia & {$[45]$} & $11.8^{*}$ \\
Estonia & {$[23]$} & 11.0 \\
Ireland & {$[36]$} & 10.7 \\
Poland & {$[43]$} & $10.7^{*}$ \\
Spain & {$[49]$} & $10.5^{*}$ \\
Netherlands & {$[39]$} & 10.4 \\
Finland & {$[25]$} & 10.3 \\
Iceland & {$[34]$} & $10.2^{*}$ \\
Norway & {$[42]$} & 10.0 \\
Italy & {$[37]$} & 9.9 \\
Hungary & {$[33]$} & $9.8^{*}$ \\
Switzerland & {$[54]$} & $9.8^{*}$ \\
Denmark & {$[22]$} & 9.7 \\
UK/England & {$[56]$} & 9.5 \\
Serbia & {$[47]$} & $9.4^{*}$ \\
Wales & {$[58]$} & 9.4 \\
Scotland & {$[46]$} & 9.3 \\
Northern Ireland & {$[41]$} & 9.1 \\
Sweden & {$[53]$} & 9.0 \\
Belgium & {$[18]$} & $8.4^{*}$ \\
Bosnia & {$[19]$} & $7.6^{*}$ \\
\hline Arthmetic &
\end{tabular}

${ }^{*}$ Arithmetic mean

by the national nutrition boards in women of reproductive age was quite similar in most countries (Table 1). Most studies used an RI/RNI/RDA of 14.8-15.0 mg/day. In Bosnia, Croatia, France, and Spain, RI/RDA/DRI was $18 \mathrm{mg} /$ day. Two Belgian studies from 2004 to 2006 quoted an RNI of $20 \mathrm{mg} /$ day, whereas the latest study from 2014 quoted an RNI of $15 \mathrm{mg} /$ day.

Table 1 shows the studies which tried to assess the percentage of women having dietary iron intake below the national recommended intake. However, there was no consistency concerning the mode of reporting data, so it is 
TABLE 4: Average requirement (AR) and reference nutrient intake (RNI) for dietary iron in women in Europe and the USA.

\begin{tabular}{|c|c|c|c|c|c|}
\hline Institution & Reference & AR (mg/day) & RNI (mg/day) & AR (mg/day) & RNI (mg/day) \\
\hline Age, years & - & $<50$ & $<50$ & $\geq 50$ & $\geq 50$ \\
\hline IOM 2001 & {$[62]$} & 8.1 & 18 & 5 & 8 \\
\hline FAO/WHO 2001 & {$[63]$} & - & $19.6^{*}$ & - & $7.5^{*}$ \\
\hline NNR 2012 & {$[64]$} & 10 & 15 & 6 & 9 \\
\hline EFSA 2015, 2017 & {$[10,11]$} & 7 & 16 & 6 & 11 \\
\hline SACN 2017 & {$[65]$} & - & 14.8 & - & 8.7 \\
\hline
\end{tabular}

${ }^{*}$ Provided 15\% iron bioavailability; IOM = Institute of Medicine (USA); FAO = Food and Agriculture Organization of the United Nations; WHO= World Health Organization; NNR = Nordic Nutrition Recommendations; EFSA = European Food Safety Authority; SACN = Scientific Advisory Committee on Nutrition (UK).

not possible to make reliable comparisons of the estimates in the various countries.

From a statistical point of view, a median or mean iron intake below the RI indicates that more than $50 \%$ of the women have an iron intake below RI. In all studies, except the Lithuanian, median or mean iron intake was below an RI of $15 \mathrm{mg}$ iron/day.

\section{Discussion}

In the comparison between countries, several confounders should be considered. The dietary methods were different in many of the studies, and they were not standardized and therefore not directly comparable. The European Food Consumption Survey Method (EFCOSUM) group concluded that "the most suitable method to get internationally comparable new data on population means and distributions of actual intake is 24 -hour recall, to be conducted at least twice" [66].

The FFQ tend to estimate higher mean intakes for most nutrients compared to the 24-hour recall [67]. In the two Swedish surveys, the regional FFQ study from Umeå [52] reported a mean dietary iron intake of $14.5 \mathrm{mg} /$ day, while the nationwide 4 days food diary study [53] reported a significantly lower intake of $9.4 \mathrm{mg} /$ day. In Croatia, the nationwide FFQ survey [20] reported a mean iron intake of $16.1 \mathrm{mg} /$ day, while a study in nearby Bosnia [19] using the 24-hour recall reported a significantly lower mean iron intake of $7.6 \mathrm{mg} /$ day. Clearly, FFQ should not be used for assessment of dietary iron intake.

Calculation of the dietary intake of micronutrients including iron is dependent on the quality and representativeness of the food composition tables. The food composition tables used to calculate dietary iron intake were in most countries based on national food databases, and the food composition could therefore vary between countries due to the different chemical methodologies used in the analyses of the various food items. For example, the Baltic Republics used old Russian food composition tables and some eastern European countries used food databases from the USA, which were "adapted to regional conditions."

Food composition tables reflect the composition of the most common staple foods available in a specific country. Usually, mandatory fortification of foods is included in the food composition tables, whereas optional fortification is not. There might in some countries exist foods which are iron-fortified on a voluntary basis, and this iron may not be included in the food composition tables. Iron-fortified foods will contribute to a higher iron nutrient density and consequently to a higher dietary iron intake. This could in part explain the differences in dietary iron intake across Europe.

Countries have different recommendations concerning iron fortification of foods. For example, UK has mandatory fortification of wheat flour (apart from wholemeal) with iron and all flours (except wholemeal) with calcium-a peculiar combination-as calcium is an inhibitor of iron absorption. Many breakfast cereals are fortified with iron on an optional basis and according to the British National Diet and Nutrition Survey, they contribute to $20 \%$ of the average iron intake of British adults. Fortification practices in Europe around 2006 were as follows: Denmark, Finland, Germany, Ireland, Italy, the Netherlands, and Spain had no mandatory iron fortification. Denmark has optional fortification with iron to certain flours and breakfast cereals, and fortification of breakfast cereals is also practiced in some other countries [68].

As seen in Table 1, the dietary iron intake expressed as the median was consistently lower than that expressed as the arithmetic mean. This indicates than iron intake in the female population does not follow a normal distribution. The distribution is skewed to the right just like the distribution of menstrual blood losses [2], the distribution of requirements for absorbed iron [69], and the distribution of the iron status biomarker serum ferritin [70]. Therefore, the distribution of iron intake would be better described with nonparametric statistics as median and $2.5-97.5$ or 5-95 percentiles. Alternatively, geometric mean and standard deviation can be used. Geometric mean \pm standard deviation is calculated as the mean \pm standard deviation of $\log _{10}$ values of iron intake. None of the studies used geometric mean values. The inconsistency of the used statistical methods impedes direct comparison of the results of different studies.

In general, the national dietary surveys did not correct for underreporting or overreporting of dietary energy intake [71]. Underreporting is assumed to be present in $20-30 \%$ of the participants, especially in women and obese persons [72]. Underreporting means that the lowest percentiles for dietary iron intake in women of reproductive age should be taken with considerable reservation. Underreporting is a confounding factor and a major limitation of self-reported dietary intake [72]. Various levels of underreporting in the different studies may contribute to the different results 
concerning dietary iron intake. Correcting for underreporting will push the population mean and median intakes upwards but could be necessary to get a more accurate picture of intakes in a population.

The variations in dietary iron intake are the resultant of different factors, of which the nutrient density for iron is important. Dietary iron intake is closely associated with nutrient density for iron (Table 3). The nutrient density for iron is dependent on the dietary habits, which differ from country to country, especially concerning the intake of meat, poultry, and fish, which contain easily absorbed heme iron vs. intake of foods containing nonheme iron, which has a lower absorption rate. Nutrient density can also be influenced by mandatory or optional fortification of various food items.

There were marked differences between median and mean dietary iron intake in the various countries, ranging from $7.6 \mathrm{mg} /$ day in Bosnia to $19 \mathrm{mg} /$ day in Lithuania. In almost all countries, more than half of the women of reproductive age had a dietary iron intake below $15 \mathrm{mg} /$ day, ranging from $61 \%$ in Ireland to $90-97 \%$ in Belgium, Denmark, Hungary, Serbia, and Sweden (Table 1). However, we found no consistent differences between dietary iron intake across the different European regions (western, middle, and eastern Europe) as also previously reported by Elmadfa [9].

The recommended intake for dietary iron was different in many countries, especially before the year 2000 (Table 1). Hereafter, there seems to be growing consensus about the RI, probably encouraged by the recommendations by national and international committees, e.g., EFSA [10] and the Nordic Nutrition Recommendations (NNR) [64]. In most studies after the year 2000, an RI/RNI/RDA for dietary iron intake of $14.8-16 \mathrm{mg} /$ day is recommended. The recommendations for dietary iron intake from different institutions in Europe and the USA [10, 11, 62-65] are listed in Table 4. According to the most recent European recommendations for dietary iron intake in women from the Scientific Advisory Committee on Nutrition in UK (SACN), NNF, and EFSA ranging from 14.8 to $16.0 \mathrm{mg} /$ day (Table 4), we have chosen to use an RNI for iron of $15.0 \mathrm{mg} /$ day in this review.

$\mathrm{RI} / \mathrm{RNI} / \mathrm{RDA}$ is used for assessment of the individual's intake, so comparing median or mean daily dietary iron intake in a female population group against the RI could overestimate the fraction of women who does not obtain their iron requirements. The estimated AR is the daily level of intake that is adequate for $50 \%$ of the individuals in a population group $[11,61]$. From this aspect, AR is an important DRV in population surveys [11]. If the median or mean iron intake is close to the AR in a female population group, then at least $50 \%$ of the women will be meeting their requirements. The higher above the AR the intake is, the greater the proportion of women that should be meeting their requirements. This assumption is valid in populations where nutrient requirements display a normal distribution. However, in women of reproductive age, individual iron requirements show great variation due the variation in menstrual blood losses [3]. Both the distributions of menstrual blood losses [2] and individual iron requirements are skewed, wherefore the estimation of AR is associated with some uncertainty. In Europe, the AR for iron in women of reproductive age is estimated to be $7 \mathrm{mg}$ according to EFSA $[10,11]$ and $10 \mathrm{mg}$ according to NNR [64]. In the USA, the $\mathrm{AR}$ is $8.1 \mathrm{mg}$ [62]. However, few studies reported the estimated AR for dietary iron, and only three studies reported the percentage of women having an iron intake below AR.

In 18- to 45-year-old Danish women, median dietary iron intake was $9.7 \mathrm{mg} /$ day [22]. Using an AR of $7 \mathrm{mg} /$ day, $13 \%$ had an intake below AR and $87 \%$ an intake equal to or above AR; from these values, it should be anticipated that most women would have an adequate iron status. Using an AR of $10 \mathrm{mg} /$ day, $54 \%$ had an intake below AR and $46 \%$ an intake equal to and above AR; this is more consistent with the fact that approximately $45 \%$ of Danish women of reproductive age have a low iron status with small or depleted body iron reserves $[3,4,70]$. Therefore, in a Scandinavian female population of reproductive age, it seems more appropriate to use an AR of $10 \mathrm{mg} /$ day than an AR of $7 \mathrm{mg} /$ day.

The discrepancies between the RI and actual dietary iron intake may be due to (1) a low nutrient density of iron in the habitual daily diet indicating (2) a low intake of heme iron contained in meat, poultry, and fish [73] and (3) a high intake of ferric nonheme iron from nonanimal foods. Other factors, which influence the absorption of the ingested dietary iron, are a relatively low intake of promotors of iron absorption including the so called "meat factors" which also enhance absorption of nonheme iron [74] and a relatively high intake of inhibitors of iron absorption such as polyphenols, phytates, and calcium. A low energy intake due to the sedentary lifestyle in the affluent western societies may also contribute to a low dietary iron intake but is difficult to balance against the increasing frequency of obesity.

The low dietary iron intake and/or the low iron bioavailability in women in Europe is reflected in their low body iron status. An overview of iron status in women of reproductive age in Europe has recently been published [8] based on data from more than 15 European countries including national surveys and relevant clinical studies. Iron status was assessed by measurement of plasma or serum ferritin and blood haemoglobin concentrations. In women of reproductive age, median or geometric mean serum ferritin concentrations were estimated at 26-38 $\mu \mathrm{g} / \mathrm{L}$. Approximately $40-55 \%$ of this population had small or depleted body iron reserves and $45-60 \%$ had "replete" iron reserves (serum ferritin $>30 \mu \mathrm{g} / \mathrm{L}$, corresponding to iron reserves of $>230 \mathrm{mg}$ ). The prevalence of ID (serum ferritin $<12-15 \mu \mathrm{g} / \mathrm{L}$ ) was $10-32 \%$, and the prevalence of IDA (serum ferritin $<12-15 \mu \mathrm{g} / \mathrm{L}$ and haemoglobin $<120 \mathrm{~g} / \mathrm{L}$ ) was $2-5 \%$. Only $20-35 \%$ of premenopausal women had sufficient iron reserves (serum ferritin $>70 \mu \mathrm{g} / \mathrm{L}$ ) to complete a normal pregnancy without needing supplementary iron [75].

\section{Limitations of This Review}

This review has several limitations, due to the heterogeneous methods used in the studies. Some studies were national and some regional, the age groups and the dietary methods differed between studies, and statistical methods were 
different-some studies used nonparametric and others parametric statistics; most studies used unweighted and some weighted data, and few studies had been corrected for underreporting; furthermore, there was an inconsistent terminology concerning the use of DRVs of dietary iron. These are all factors, which impair comparison of the results of the various studies. Furthermore, the food composition tables varied from country to country, and the contribution of voluntary food iron fortification was not evaluated in the studies.

\section{Conclusions}

This review demonstrates that, in Europe, a high proportion of women of reproductive age have a dietary iron intake below $15 \mathrm{mg} /$ day. The relatively low iron intake may contribute to the low body iron status found in many women in Europe [8].

In European countries and within the European Union, there is a definite need for development and implementation of common standardized dietary methods [66] and for standardization of food composition tables as recently introduced by EFSA [76]. It is also important to obtain consensus on the use of the different DRVs [61] and to implement the use of uniform statistical methods in order to obtain reliable intercountry comparisons of dietary intakes of macro- and micronutrients.

\section{Conflicts of Interest}

The author declares that there are no conflicts of interest.

\section{Acknowledgments}

This research was supported by an unrestricted grant from Pharmovital ApS, Rosenkæret 11B, DK-2860-Søborg, Denmark. The author appreciates the assistance of Senior Advisor Sisse Fagt, Danish National Food Institute, in analysis of dietary iron in the Danish National Surveys on Diet and Physical Activity; Professor Inge Tetens, VitalityCentre for Good Older Lives, Department of Nutrition, Exercise, and Sports, University of Copenhagen, Denmark, for information on food iron fortification and the EFSA database; and the assistance of Márta Bakacs, MSc, and Eszter Sarkadi Nagy, PhD, Hungarian National Institute of Pharmacy and Nutrition, in the statistical analysis of dietary iron intake in the Hungarian surveys.

\section{References}

[1] G. J. Anderson and D. M. Frazer, "Current understanding of iron homeostasis," American Journal of Clinical Nutrition, vol. 106, no. 6, pp. 1559S-1566S, 2017.

[2] L. Hallberg, L. Nilsson, A.-M. Höghdal, and G. Rybo, "Menstrual blood losses in a population sample," Acta Obstetricia et Gynecologica Scandinavica, vol. 43, no. 7, 57 pages, 1965.

[3] N. Milman, N. Rosdahl, N. Lyhne, T. Jørgensen, and N. Graudal, "Iron status in Danish women aged 35-65 years: relation to menstruation and method of contraception," Acta
Obstetricia et Gynecologica Scandinavica, vol. 72, no. 8, pp. 601-605, 1993.

[4] N. Milman, M. Kirchhoff, and T. Jørgensen, "Iron status markers, serum ferritin and hemoglobin in 1359 Danish women in relation to menstruation, hormonal contraception, parity, and postmenopausal hormone treatment," Annals of Hematology, vol. 65, no. 2, pp. 96-102, 1992.

[5] N. Milman, "Anemia-still a major health problem in many parts of the world!," Annals of Hematology, vol. 90, no. 4, pp. 369-377, 2011.

[6] N. Milman, P. Pedersen, T. á Steig, K.-E. Byg, N. Graudal, and K. Fenger, "Clinically overt hereditary hemochromatosis in Denmark 1948-1985: epidemiology, factors of significance for long-term survival, and causes of death in 179 patients," Annals of Hematology, vol. 80, no. 12, pp. 737-744, 2001.

[7] World Health Organization, The Global Prevalence of Anaemia in 2011, World Health Organization, Genève, Switzerland, 2015, http://www.who.int/nutrition/publications/micronutrients/ global_prevalence_anaemia_2011/en/.

[8] N. Milman, C. L. Taylor, J. Merkel, and P. M. Brannon, "Iron status in pregnant women and women of reproductive age in Europe," American Journal of Clinical Nutrition, vol. 106, no. 6, pp. S1655-S1662, 2017.

[9] I. Elmadfa, European Nutrition and Health Report, Karger, Basel, Switzerland, 2009.

[10] European Food Safety Authority (EFSA), "Scientific opinion on dietary reference values for iron. EFSA panel on dietetic products, nutrition and allergies," EFSA Journal, vol. 13, no. 10, p. 4254, 2015.

[11] European Food Safety Authority (EFSA), "Dietary reference values for nutrients. Summary report," Technical Report, 2017.

[12] M. Blanquer, A. García-Álvarez, L. Ribas-Barba et al., "How to find information on national food and nutrient consumption surveys across Europe: systematic literature review and questionnaires to selected country experts are both good strategies," British Journal of Nutrition, vol. 101, no. 2, pp. S37-S50, 2009.

[13] V. Szücs, E. Szabó, and D. Bánáti, "Short overview of food consumption databases," Czech Journal of Food Sciences, vol. 31, no. 6, pp. 541-546, 2013.

[14] I. Elmadfa, Austrian Nutrition Report, Institute of Nutrition, University of Vienna, Austria, Vienna, 1st edition, 2009.

[15] I. Elmadfa, Austrian Nutrition Report, Institute of Nutrition, University of Vienna, Austria, Vienna, 1st edition, 2012.

[16] S. Devriese, I. Huybrechts, M. Moreau, and H. Van Oyen, "The Belgian Food Consumption Survey," WIV/EPI Reports N 2006, Scientific Institute for Public Health, Uccle, Belgium, 2016.

[17] I. Pynaert, J. Delanghe, M. Temmerman, and S. De Henauw, "Iron intake in relation to diet and iron status of young adult women," Annals of Nutrition and Metabolism, vol. 51, no. 2, pp. 172-181, 2007.

[18] S. Bel and J. Tafforeau, "The belgian food consumption survey 2014-2015,” Report 4, WIV-ISP, Brussel, Belgium, 2016.

[19] V. Alibabić, E. Šertović, I. Mujić, J. Živković, M. Blažić, and S. Zavadlav, "The level of nutrition and dietary iron intake of Bosnian women," Procedia-Social and Behavioral Sciences, vol. 217, pp. 1071-1075, 2016.

[20] Z. Šatalić, I. C. Barić, and I. Keser, "Diet quality in Croatian university students: energy, macronutrient and micronutrient intakes according to gender," International Journal of Food Sciences and Nutrition, vol. 58, no. 5, pp. 398-410, 2007. 
[21] Dietary Habits in Denmark 2003-2008, Main Results, The National Food Institute, Danish Technical University, Kongens Lyngby, Denmark, 1st edition, 2019, http://www.food.dtu.dk.

[22] Dietary Habits in Denmark 2011-2013, Main results, The National Food Institute, Danish Technical University, Kongens Lyngby, Denmark, 1st edition, February 2015, http:// www.food.dtu.dk.

[23] World Health Organization, Nutrition and Lifestyle in the Baltic Republics, European Centre on Health of Societies in Transition and World Health Organization Regional Office for Europe, Geneva, Switzerland, 1999.

[24] M. Lahti-Koski, L. M. Valsta, G. Alfthan, H. Tapanainen, and A. Aro, "Iron status of adults in the capital area of Finland," European Journal of Nutrition, vol. 42, no. 5, pp. 287-292, 2003.

[25] A. Helldán, M. Kosonen, and H. Tapanainen, “The national FINDIET 2012 survey," Report No. 16, Helsinki: National Institute for Health and Welfare, Helsinki, Finland, 2013.

[26] P. Galan, H.-C. Yoon, P. Preziosi et al., "Determining factors in the iron status of adult women in the SU.VI.MAX study," European Journal of Clinical Nutrition, vol. 52, no. 6, pp. 383-388, 1998.

[27] C. Dubuisson, S. Lioret, M. Touvier et al., "Trends in food and nutritional intakes of French adults from 1999 to 2007: results from the INCA surveys," British Journal of Nutrition, vol. 103, no. 7, pp. 1035-1048, 2010.

[28] G. B. M. Mensink and R. Beitz, "Food and nutrient intake in East and west Germany, 8 years after the reunification-the German nutrition survey 1998," European Journal of Clinical Nutrition, vol. 58, no. 7, pp. 1000-1010, 2004.

[29] G. Mensink, M. Burger, R. Beitz, Y. Henschel, and B. Hintzpeter, Contributions to Health Reporting in the Federal Republic of Germany. What Do We Eat Today? Dietary Behavior in Germany, Robert-Koch-Institut, Berlin, Germany, 2002.

[30] N. Verzehrsstudie, National Food Consumption Study II. Report of Results, Part 2. The Nationwide Survey on the Nutrition of Adolescents and Adults, Max-Rubner Institute. Federal Research Institute of Nutrition and Food, Karlsruhe, Germany, 2008.

[31] L. Biró, G. Zajkás, E. Greiner et al., "Hungarian national dietary survey, 2003-2004," Orvosi Hetilap, vol. 148, no. 15, pp. 703-708, 2007.

[32] A. Lugasi, E. Sarkadi Nagy, A. Zentai et al., "Hungarian diet and nutritional status survey-the OTAP2009 study V. Microelement intake of the Hungarian population," Orvosi Hetilap, vol. 153, no. 30, pp. 1177-1184, 2012.

[33] B. Nagy, Z. Nagy-Lőrincz, M. Bakacs, É. Illés, N. E. Sarkadi, and E. Martos, "Hungarian Diet and Nutritional Status Survey-The OTAP 2014 Study. V. Microelement intake of the Hungarian population," Orvosi Hetilap, vol. 158, no. 21, pp. 803-810, 2017.

[34] H. Thorgeirsdottir, H. Valgeirsdottir, and I. Gunnarsdottir, National Dietary Survey of the Icelandic Nutrition Council 2010-2011. Main Findings: Directorate of Health, Icelandic Food and Veterinary Authority and Unit for Nutrition Research, University of Iceland, Reykjavik, Iceland, 2011.

[35] Irish Universities Nutrition Alliance (IUNA), The NorthSouth Ireland Food Consumption Survey, Food Safety Promotion Board, Dublin, Ireland, 2001, http://www.iuna.net.

[36] Irish Universities Nutrition Alliance (IUNA), "National adult nutrition survey 2011," January 2019, http://www.ucd.ie/ t4cms/IUNA\%20summaryreport_final.pdf.
[37] C. Leclercq, D. Arcella, R. Piccinelli, S. Sette, C. Le Donne, and A. Turrini, On Behalf of the INRAN-SCAI 2005-06 Study Group, "The italian national food consumption survey INRAN-SCAI 2005-06: main results in terms of food consumption," Public Health Nutrition, vol. 12, no. 12, pp. 2504-2532, 2009.

[38] J. H. Brussard, H. A. Brants, M. Bouman, and M. R. H. Löwik, "Iron intake and iron status among adults in The Netherlands," European Journal of Clinical Nutrition, vol. 51, no. 3, pp. S51-S58, 1997.

[39] K. F. A. M. Hulshof and A. G. Kruizinga, Additional Calculations Related to the Consumption of Various Visible Fats and the Contribution to the Intake of Selected Nutrients. Food Consumption Survey 1997-1998 and Ten Year Trend, TNO Voeding TNO-Rapport V, Zeist, Netherlands, 1999.

[40] C. van Rossum, H. P. Fransen, J. Verkaik-Kloosterman, E. J. M. Buurma-Rethans, and M. C. Ocké, Dutch National Food Consumption Survey 2007-2010, National Institute for Public Health and the Environment, Ministry of Health, Wellfare and Sport, Bilthoven, Netherland, 2011, https:// www.rivm.nl/bibliotheek/rapporten/350050005.pdf.

[41] B. Bates, A. Lennox, A. Prentice et al., National Diet and Nutrition Survey Rolling Programme (NDNS RP) Results from Years 1-4 (Combined) for Northern Ireland (2008/09-2011/ 12). A Survey Carried Out on Behalf of the Food Standards Agency in Northern Ireland and Public Health England, Food Standards Agency (food.gov.uk) and Department of Health, Social Services and Public Safety, Northern Ireland, UK, 2015.

[42] T. H. Totland, B. K. Melnæs, N. Lundberg-Hallén et al., A National Nutrition Survey Among Men and Women in Norway in the Age of 18-60 Years, in the Years 2010-2011, National Institute of Health, Bethesda, MD, USA, 2012, http:// www.helsedirektoratet.

[43] L. Szponar, W. Sekula, M. Nelson, and R. C. Weisell, “The household food consumption and anthropometric survey in Poland," Public Health Nutrition, vol. 4, pp. 1183-1186, 2001.

[44] E. Pinto, H. Barros, and I. D. S. Silva, "Dietary intake and nutritional adequacy prior to conception and during pregnancy: a follow-up study in the north of Portugal," Public Health Nutrition, vol. 12, pp. 922-931, 2009.

[45] L. Kohlmeier, M. Mendez, S. Shalnova, A. Martinchik, H. Chakraborty, and M. Kohlmeier, "Deficient dietary iron intakes among women and children in Russia: evidence from the russian longitudinal monitoring survey," American Journal of Public Health, vol. 88, no. 4, pp. 576-580, 1998.

[46] B. Bates, A. Lennox, A. Prentice et al., National Diet and Nutrition Survey Rolling Programme (NDNS RP). Results from Years 1-4 (combined) for Scotland (2008/09-2011/12). A Survey Carried Out on Behalf of the Food Standards Agency in Scotland and Public Health England, Food Standards Agency (food.gov.uk) and Department of Health, Social Services and Public Safety, Northern Ireland, UK, 2015.

[47] M. Knez, M. Nikolic, M. Zekovic, J. C. R. Stangoulis, M. Gurinovic, and M. Glibetic, "The influence of food consumption and socio-economic factors on the relationship between zinc and iron intake and status in a healthy population," Public Health Nutrition, vol. 20, no. 14, pp. 24862498, 2017.

[48] K. Babinská and A. Béderová, "Changes in nutrient intake in the adult population of the Slovak Republic," Journal of Food Composition and Analysis, vol. 15, no. 4, pp. 359-365, 2002.

[49] L. Serra-Majem, L. Ribas-Barba, G. Salvador et al., "Trends in energy and nutrient intake and risk of inadequate intakes in 
Catalonia, Spain (1992-2003)," Public Health Nutrition, vol. 10, no. 11, pp. 1354-1367, 2007.

[50] M. E. Quintas, A. M. Requejo, R. M. Ortega, M. R. Redondo, A. M. López-Sobaler, and M. J. Gaspar, "The female Spanish population: a group at risk of nutritional iron deficiency," International Journal of Food Sciences and Nutrition, vol. 48, no. 4, pp. 271-279, 1997.

[51] M. Samaniego-Vaesken, T. Partearroyo, J. Olza et al., "Iron intake and dietary sources in the Spanish population: findings from the ANIBES study," Nutrients, vol. 9, no. 3, pp. 203-214, 2017.

[52] A. Lundqvist, I. Johansson, A. L. Wennberg et al., "Reported dietary intake in early pregnant compared to non-pregnant women-a cross-sectional study," BMC Pregnancy and Childbirth, vol. 14, no. 1, 373 pages, 2014.

[53] Riksmaten Vuxna 2010-2011, "Food and nutrient intake in adults in Sweden 2010-2011," Livsmedelsverket (National Institute of Nutrition), Uppsala, Sweden, 2019, http://www. livsmedelsverket.se/globalassets/matvanor-halsa-miljo/kostradmatvanor/matvaneundersokningar/riksmaten_2010_20111.pdf.

[54] D. Abreu, I. Cardoso, J.-M. Gaspoz, I. Guessous, and P. Marques-Vidal, "Trends in dietary intake in Switzerland, 1999-2009," Public Health Nutrition, vol. 17, no. 3, pp. 479485, 2013.

[55] C. Whitton, S. K. Nicholson, C. Roberts et al., "National diet and nutrition survey: UK food consumption and nutrient intakes from the first year of the rolling programme and comparisons with previous surveys," British Journal of $\mathrm{Nu}$ trition, vol. 106, no. 12, pp. 1899-1914, 2011.

[56] Public Health England and Food Standards Agency, "National diet and nutrition survey," May 2014, https:/www.gov.uk/ government/statistics/national-diet-and-nutrition-survey-resultsfrom-years-1-to-4-combined-of-the-rolling-programme-for2008-and-2009-to-2011-and-2012.

[57] Public Health England and Food Standards Agency, "National diet and nutrition survey. Results of the national diet and nutrition survey (NDNS) rolling programme for 2012 to 2013 and 2013 to 2014," January 2019, https://www.gov.uk/government/ statistics/ndns-results-from-years-5-and-6-combined.

[58] B. Bates, A. Lennox, A. Prentice et al., National Diet and Nutrition Survey Rolling Programme (NDNS RP) Results from Years 2-5 (combined) for Wales (2009/10-2012/13). A Survey Carried Out on Behalf of the Food Standards Agency in Wales, Welsh Government and Public Health England, Food Standards Agency (food.gov.uk) and Welsh Government, Cardiff, UK, 2015.

[59] European Commission, "Eurostat. Teenage and older mothers in the EU," April 2019, https://ec.europa.eu/eurostat/web/productseurostat-news/-/DDN-20170808-1?inheritRedirect=true.

[60] E. B. Gold, "The Timing of the age at which natural menopause occurs," Obstetrics and Gynecology Clinics of North America, vol. 38, no. 3, pp. 425-440, 2011.

[61] EFSA Panel on Dietetic Products, Nutrition and Allergies, "Scientific opinion for deriving and applying dietary reference values," European Food Safety Authority Journal, vol. 8, no. 3, 1458 pages, 2010.

[62] Institute of Medicine, Food and Nutrition Board. Dietary Reference Intakes for Vitamin A, Vitamin K, Arsenic, Boron, Chromium, Copper; Iodine, Iron, Manganese, Molybdenum, Nickel, Silicon, Vanadium, and Zinc, National Academic Press, Washington, DC, USA, 2001.

[63] Food and Agricultural Organization of the United Nations and World Health Organization, Human Vitamin and Mineral Requirements: Report of a Joint FAO/WHO Expert
Consultation, FAO Food and Nutrition Division, Bangkok, Thailand, 2001.

[64] Nordic Council of Ministers, Nordic Nutrition Recommendations 2012: Integrating Nutrition and Physical Activity, Nordic Council of Ministers, Copenhagen, Denmark, 2019, http://dx.doi.org/10.6027/Nord2014-002.

[65] British Nutrition Foundation, "Nutrient requirements 2016," January 2019, https://www.nutrition.org.uk/attachments/article/ 907/Nutrition\%20Requirements_Revised\%20Oct\%202017.pdf.

[66] J. Brussaard, L. Johansson, and J. Kearney, "Rationale and methods of the EFCOSUM project," European Journal of Clinical Nutrition, vol. 56, no. 2, pp. S4-S7, 2002.

[67] V. Coathup, S. Wheeler, and L. Smith, "A method comparison of a food frequency questionnaire to measure folate, choline, betaine, vitamin $\mathrm{C}$ and carotenoids with 24 -h dietary recalls in women of reproductive age," European Journal of Clinical Nutrition, vol. 70, no. 3, pp. 346-351, 2016.

[68] A. Flynn, T. Hirvonen, G. B. M. Mensink et al., "Intake of selected nutrients from foods, from fortification and from supplements in various European countries," Food \& $\mathrm{Nu}$ trition Research, vol. 53, 2009.

[69] L. Hallberg and L. Rossander-Hultén, "Iron requirements in menstruating women," American Journal of Clinical Nutrition, vol. 54, no. 6, pp. 1047-1058, 1991.

[70] N. Milman, K.-E. Byg, L. Ovesen, M. Kirchhoff, and K. S.-L. Jürgensen, "Iron status in Danish women, 1984-1994: a cohort comparison of changes in iron stores and the prevalence of iron deficiency and iron overload," European Journal of Haematology, vol. 71, no. 1, pp. 51-61, 2003.

[71] W. Becker and D. Welten, "Under-reporting in dietary surveys-implications for development of food-based dietary guidelines," Public Health Nutrition, vol. 4, no. 2b, pp. 683687, 2001.

[72] L. Gemming, Y. Jiang, B. Swinburn, J. Utter, and C. N. Mhurchu, "Under-reporting remains a key limitation of self-reported dietary intake: an analysis of the 2008/09 New Zealand adult nutrition survey," European Journal of Clinical Nutrition, vol. 68, no. 2, pp. 259-264, 2014.

[73] A. R. West and P. S. Oates, "Mechanisms of heme iron absorption: current questions and controversies," World Journal of Gastroenterology, vol. 14, no. 26, pp. 4101-4110, 2008.

[74] R. F. Hurrell, M. B. Reddy, M. Juillerat, and J. D. Cook, "Meat protein fractions enhance nonheme iron absorption in humans," Journal of Nutrition, vol. 136, no. 11, pp. 2808-2812, 2006.

[75] N. Milman, "Iron in pregnancy-how do we secure an appropriate iron status in the mother and child?," Annals of Nutrition and Metabolism, vol. 59, no. 1, pp. 50-54, 2011.

[76] European Food Safety Authority (EFSA), "Food composition data Europe (Finland, France, Germany, Italy, Netherlands, Sweden, UK). Food composition tables," January 2019, https:// www.efsa.europa.eu/en/microstrategy/food-composition-data. 


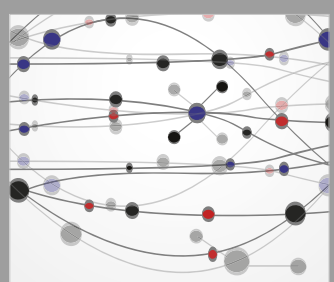

The Scientific World Journal
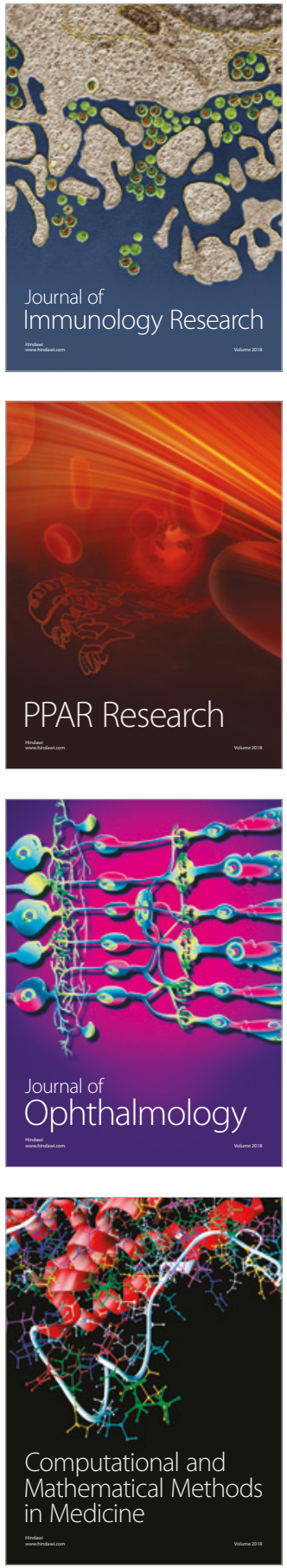

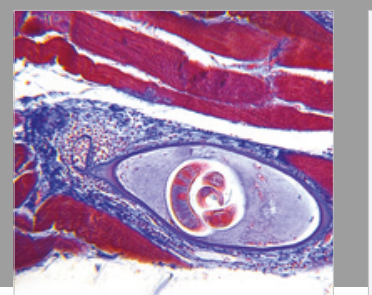

Gastroenterology Research and Practice

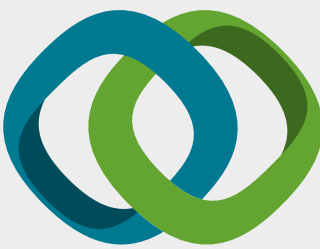

\section{Hindawi}

Submit your manuscripts at

www.hindawi.com
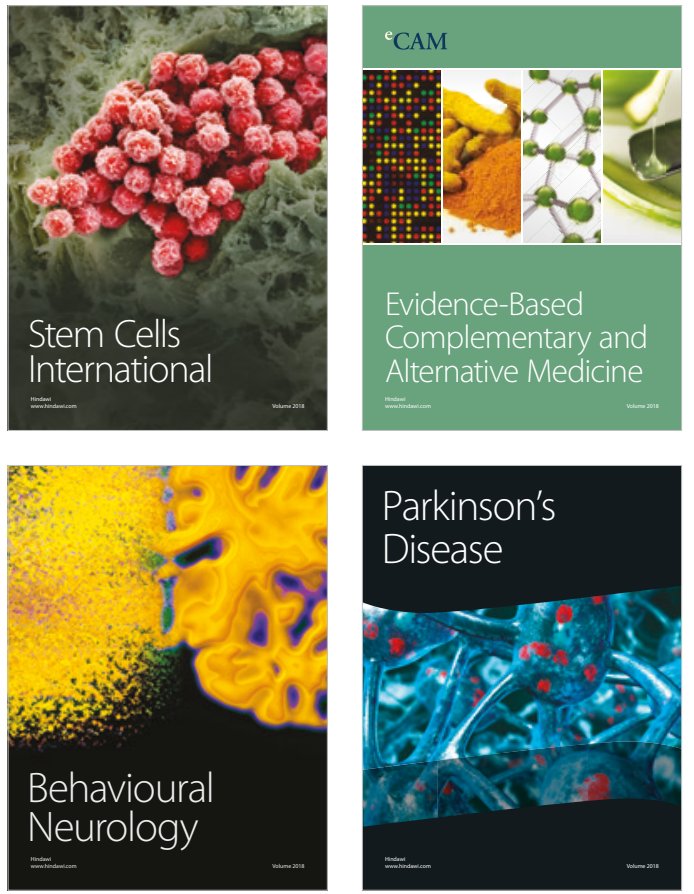

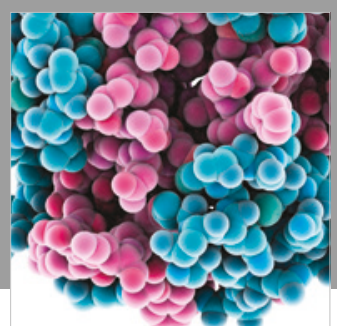

ournal of

Diabetes Research

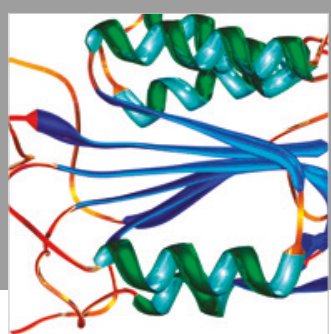

Disease Markers
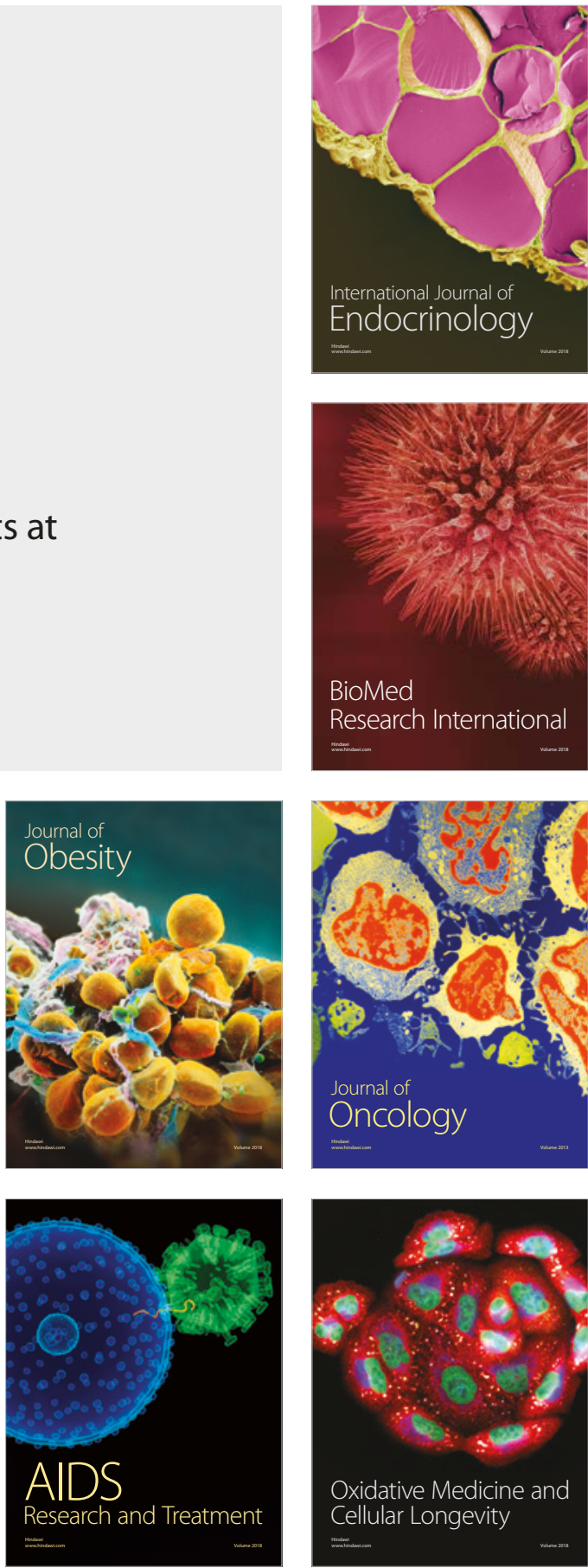